\title{
Recent activities of ITER gyrotron development in QST
}

\author{
Y.Oda $^{1}$, R. Ikeda ${ }^{1}$, K. Takahashi ${ }^{1}$, K. Kajiwara ${ }^{1}$, T. Kobayashi $^{1}$, K. Sakamoto ${ }^{1}$, S. Moriyama ${ }^{1}$, \\ C. Darbos ${ }^{2}$, and M. Henderson ${ }^{2}$ \\ ${ }^{1}$ National Institute for Quantum and Radiological Science and Technology, Naka, Japan oda.yasuhisa@qst.go.jp \\ ${ }^{2}$ ITER Organization, St-Paul-lez-Durance, France
}

\section{Introduction}

QST is committed to the development of high power RF power sources (or gyrotrons) for plasma heating in fusion devices. Our main activity is the development of $170 \mathrm{GHz}$ gyrotron for electron cyclotron resonance heating and current drive (EC H\&CD) system of ITER project which requires $20 \mathrm{MW}$ of power injection into fusion plasma. In ITER, 24 sets of $1 \mathrm{MW}$ gyrotrons are planned to be installed of which Japan procures 8 sets. QST (previous JAEA) has already demonstrated 1MW$800 \mathrm{~s}-55 \%$, $0.8 \mathrm{MW}-1 \mathrm{hr}-57 \%$ with the $\mathrm{TE}_{31,8}$ mode gyrotron [1] and also demonstrated $>1 \mathrm{MW}$ operation with $\mathrm{TE}_{31,11}$ mode gyrotron, which can generate higher power than previous design. Now the QST-ITER gyrotron has finished its designing phase and proceeds to manufacturing and test phase. The next stage of R\&D activity in QST aimed multi frequency operation including $>200$ $\mathrm{GHz}$ frequency region, for future fusion devices such as DEMO. In this paper, present status of these gyrotron developments are described.

\section{Status of ITER gyrotron}

An electron cyclotron heating and current drive system in ITER is designed to inject RF power of $20 \mathrm{MW}$ to actively control plasmas. The RF power is supplied by 24 gyrotrons. QST procures to supply 8 gyrotrons which produce $170 \mathrm{GHz} / 1 \mathrm{MW}$ each in addition 1 equatorial launcher for ITER.

The specification of ITER gyrotron is $170 \mathrm{GHz} /$ $1 \mathrm{MW}$ output / 50\% efficiency / 3600s pulse duration. The oscillation mode in the cavity is $\mathrm{TE}_{31,11}$ mode to keep marginal heat load on the cavity surface. The internal mode converter was optimized for $170 \mathrm{GHz}$ single frequency operation. The triode electron gun is utilized and the operation of high frequency power modulation up to 5 $\mathrm{kHz}$ is achieved by control of anode voltage.

The final design review of the gyrotron was held in 2015 and the gyrotron design was approved for manufacturing. Manufacturing of auxiliary components for gyrotron operation system, for example the super conducting magnets (SCM), started in 2015 and first two sets of SCMs were delivered to QST test stand in the beginning of 2016. In 2016, the first set of two gyrotrons was manufactured by Toshiba Electron Tube \& Devices (TETD) and the tubes were delivered to QST Naka Fusion Institute. Figure 1 shows the photograph of ITER gyrotron.

The short pulse test of the first ITER gyrotron has started since 2017 April after preparation of test stand. A new anode and body power supply system, which has the same configuration with ITER high voltage power supply (HVPS) system was installed into the gyrotron test stand. The new power supply system consists of DC HVPS de- vices that generate the high voltage and incorporates the switching components for $5 \mathrm{kHz}$ modulations as required for controlling the applied HV to the gyrotrons. The ITER gyrotron was installed into the test stand with ITER SCM and has achieved $1 \mathrm{~ms}$ pulse duration at $170 \mathrm{GHz}$ oscillation and a single peak Gaussian profile beam.

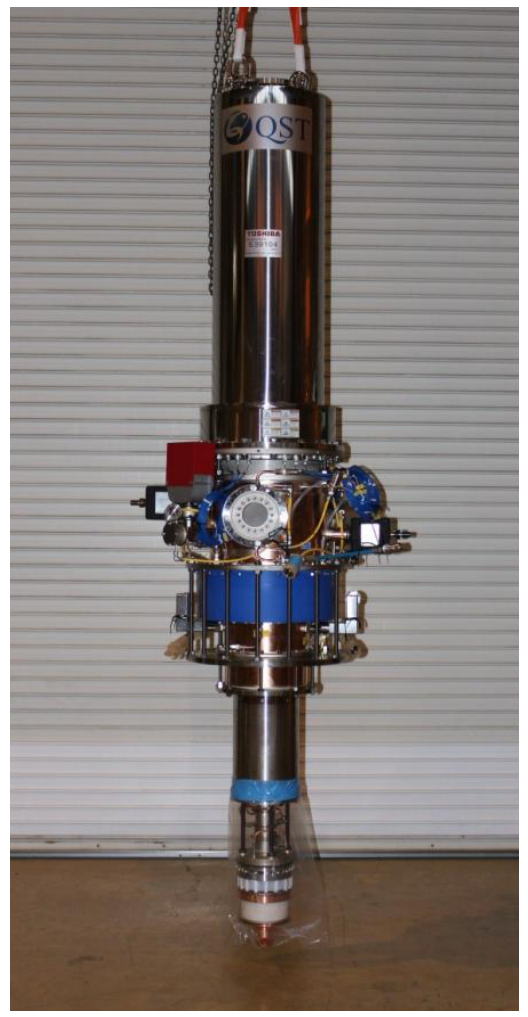

Fig. 1. Photograph of the ITER gyrotron

\section{Development of multi frequency gyrotron}

A gyrotron with $\mathrm{TE}_{31,11}$ mode cavity is suitable for multi frequency as the radiation angle out of the internal launcher as well as beam directivity from the diamond window is compatible with the mode group of $\mathrm{TE}_{19,7^{-}}$ $\mathrm{TE}_{25,9}-\mathrm{TE}_{31,11}-\mathrm{TE}_{37,13}-\ldots$. And, injection beam radii into the cavity resonator to excite these modes are $9.25 \mathrm{~mm}$ $\left(\mathrm{TE}_{19,7}\right), 9.19 \mathrm{~mm}\left(\mathrm{TE}_{25,9}\right), 9.13 \mathrm{~mm}\left(\mathrm{TE}_{31,11}\right)$ and 9.10 $\mathrm{mm}\left(\mathrm{TE}_{37,13}\right)$ and are controllable using a gun magnet around the magnetron injection gun (MIG). In addition, gyrotrons with a triode MIG have capability to optimize the pitch factor, the ratio of parallel and perpendicular electron velocities, to adapt different magnetic field profile. The oscillation frequencies of $\mathrm{TE}_{19,7}-\mathrm{TE}_{25,9^{-}}-\mathrm{TE}_{31,11^{-}}$ $\mathrm{TE}_{37,13}$ are $104 \mathrm{GHz}, 137 \mathrm{GHz}, 170 \mathrm{GHz}$ and $203 \mathrm{GHz}$, respectively and are matched for the diamond window transmission frequencies of $102 \mathrm{GHz}, 136 \mathrm{GHz}, 170 \mathrm{GHz}$ and $204 \mathrm{GHz}$ for a window thickness of $1.853 \mathrm{~mm}$. 
(a)
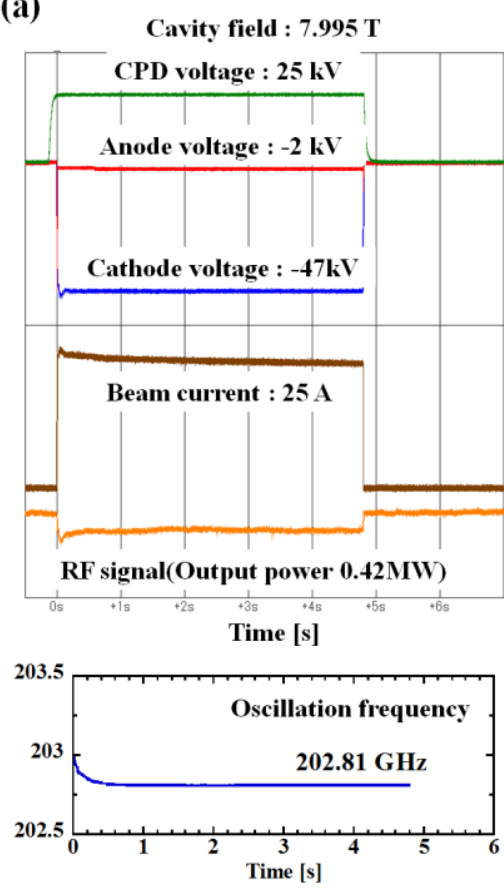

(b)
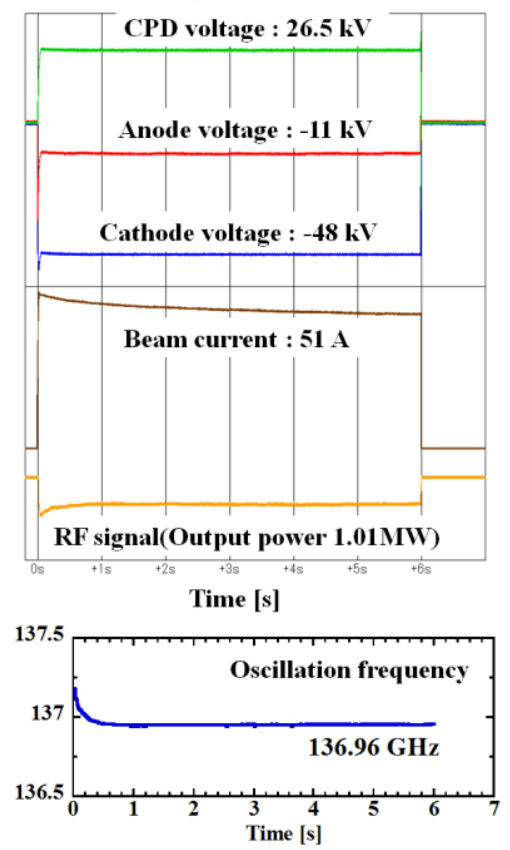

(c)

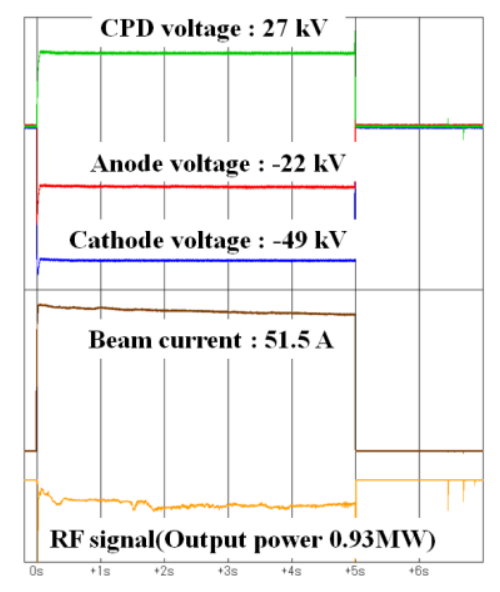

Time [s]

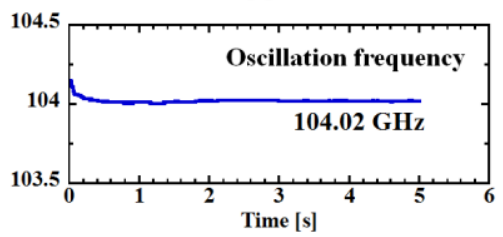

Fig. 2. Time histories of long pulse operations for $(a) \mathrm{TE}_{37,13}$ mode, (b) $\mathrm{TE}_{25,9}$ mode and $(c) \mathrm{TE}_{19,7}$ mode

The operation of $\mathrm{TE}_{31,11}$ mode/170 GHz has demonstrated 1.23 MW with an electrical efficiency of $47 \%$ for $2 \mathrm{~s}$, and $1.17 \mathrm{MW}, 45 \%$ for $5 \mathrm{~s}$. For stable long pulse operations $1.02 \mathrm{MW} / 46 \%$ oscillation for $300 \mathrm{~s}$ was demonstrated.

The operation of the $\mathrm{TE}_{19,7}$ mode, $\mathrm{TE}_{25,9}$ mode, and $\mathrm{TE}_{37,13}$ have also been demonstrated with the measured beam profile was relatively circular and centered on the output window for the other thee frequencies. The results include $1 \mathrm{MW}$ output power for $2 \mathrm{~s}$ pulse was achieved at $\mathrm{TE}_{19,7}$ mode $(136.8 \mathrm{GHz}) ; \mathrm{TE}_{25,9}$ mode $(103.9 \mathrm{GHz})$ very short pulse of $0.3 \mathrm{~ms}$ of $\mathrm{TE}_{37,13}(202.96 \mathrm{GHz})$ of $0.9 \mathrm{MW}$. This was achieved at beam voltage of $75 \mathrm{kV}$, beam current of $65 \mathrm{~A}$, and a magnetic field of $7.94 \mathrm{~T}$. And $4.8 \mathrm{~s}$ pulse operation has achieved the output power of $0.42 \mathrm{MW}$ and an electrical efficiency of $38 \%$. The beam voltage and beam current of this operation are $72 \mathrm{kV}$ (CPD voltage $25 \mathrm{kV}$ ) and $25 \mathrm{~A}$, respectively. $1 \mathrm{MW}$-level tests will be started soon. Figure 2 (a) shows the time history of long pulse operation with $\mathrm{TE}_{37,13}$ mode.
The extension of pulse length for $137 \mathrm{GHz}$ and 104 $\mathrm{GHz}$ oscillations were carried out as shown in Fig. 2 (b) and (c), which show the time history of $137 \mathrm{GHz}$ and 104 $\mathrm{GHz}$, respectively. Up to now, the output power of 1.01 MW for $6 \mathrm{~s}$ was achieved and the total efficiency of $41 \%$ was obtained in the $137 \mathrm{GHz}$ oscillation. In the $104 \mathrm{GHz}$ oscillation, the output power of $1 \mathrm{MW} / 41 \%$ for $2 \mathrm{~s}$ and $0.93 \mathrm{MW} / 37 \%$ for $5 \mathrm{~s}$ were achieved. In these shots, adjustment of a magnetic field strength was not yet performed because the beam current was rapidly decreased by cathode cooling effect. Therefore, the improvement of the efficiency by applying the magnetic field control in longer pulse length can be expected.

\section{References}

1. K. Sakamoto et al., Nat. Phys. 3, 411 (2007).

2. R. Ikeda et al., Fusion Eng. Des. 96-97, 482 (2015).

3. K. Kajiwara et al., Appl. Phys. Express 4, 126001 (2011).

4. R. Ikeda et al., submitted to J. Infrared Millim. Teraherz Waves. 